\title{
War Trauma, Child Labor, and Family Violence: Life Adversities and PTSD in a Sample of School Children in Kabul
}

\author{
Claudia Catani \\ Department of Psychology, University of Bielefeld, Bielefeld, Germany and Vivo Foundation, \\ Ancona, Italy \\ Elisabeth Schauer \\ Vivo Foundation, Ancona, Italy \\ Thomas Elbert \\ Department of Psychology, University of Konstanz, Konstanz, Germany and Vivo Foundation, \\ Ancona, Italy \\ Inge Missmahl \\ Caritas International, Kabul, Afghanistan \\ Jean-Paul Bette \\ Department of Psychology, University of Konstanz, Konstanz, Germany \\ Frank Neuner \\ Department of Psychology, University of Bielefeld, Bielefeld, Germany and Vivo Foundation, \\ Ancona, Italy
}

\begin{abstract}
The extent of cumulative adverse childhood experiences such as war, family violence, child labor, and poverty were assessed in a sample of school children (122 girls, 165 boys) in Kabul, Afghanistan. Strong gender differences were found with respect to both the frequency of such experiences and the association of different types of stressors with posttraumatic stress disorder (PTSD) symptoms. Boys reported higher overall amounts of traumatic events, specifically experiences of violence at home. This was reflected in a 26\% prevalence of probable PTSD in boys compared to $14 \%$ in girls. Child labor emerged as a common phenomenon in the examined sample and was furthermore associated with an increased likelihood of experiencing family violence for girls. The results suggest that the interplay of multilevel stressors in Afghan children contributes to a higher vulnerability for the development of PTSD.
\end{abstract}

A quarter of a century of conflict in Afghanistan has led to a countless number of civilian casualties and displacement among Afghan nationals. Despite the first democratic elections in 2005, security has not yet returned to the country. Hundreds of Afghans have died in disputes over recent years, and violence and threats by the Taliban and other militants continue to destabilize peace and the safety of the civilian population. A great number of families are impoverished and lack the necessities such as food and shelter. As a result, children become a particularly vulnerable group as they have to suffer not only from the direct consequences of war experiences, but also from indirect burdens such as malnutrition, ill health (Mashal et al., 2008), and lack of education. A recent report by the United Nations Children's Fund (UNICEF, 2007) stated that Afghanistan had the third highest under-5 mortality

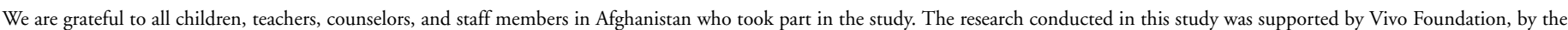

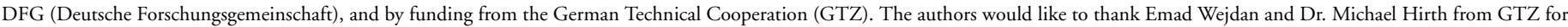

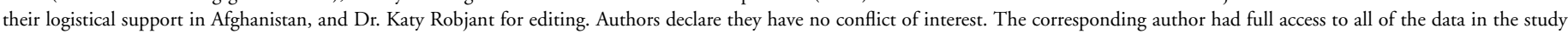
and takes responsibility for the integrity of the data and the accuracy of the data analysis.

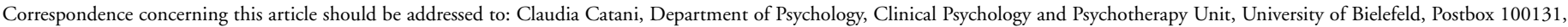
33501 Bielefeld, Germany. E-mail:claudia.catani@uni-bielefeld.de.
} 
rate worldwide, which is considered to be a critical indicator of the general well-being of children. According to the same report, attendance rates for primary and secondary school in Afghanistan are $66 \%$ and $18 \%$ for boys and $40 \%$ and $6 \%$ for girls, respectively. The appalling condition of the Afghan education system, both past and present, is reflected in an adult literacy rate of $43 \%$ for men and only $13 \%$ for women (UNICEF, 2007).

Previous studies evaluating the mental health status of Afghans exposed to the violent conflict reported a high incidence of traumatic experiences as well as psychopathology in adults (Cardozo et al., 2004; Rasekh, Bauer, Manos, \& Iacopino, 1998; Scholte et al., 2004). To our knowledge, there have been no studies to date, which have systematically addressed the mental health of school-aged children living in Afghanistan. However, surveys on adolescents and young adult Afghan refugees in the United States have found high rates of posttraumatic stress disorder (PTSD) and depression (Mghir, Freed, Raskin, \& Katon, 1995; Mghir \& Raskin, 1999) indicating that children and adolescents who currently live in Afghanistan might also be severely affected by trauma-related mental health problems.

Furthermore, studies investigating the psychological consequences of war on children currently living in conflict regions have shown increased rates of mental disorders in traumatized children, particularly PTSD. Statistics range from 25\% PTSD prevalence among Palestinian children during war conflict (Thabet, Abed, \& Vostanis, 2004) to a $41 \%$ PTSD prevalence rate in children living in Sarajevo during the Bosnian war (Allwood, Bell-Dolan, \& Husain, 2002). A survey conducted with Rwandan orphans 10 years after the genocide found that $44 \%$ of the youth was still suffering from PTSD (Schaal \& Elbert, 2006) thus revealing the chronic nature of the mental health problems in children due to the war.

Of particular relevance is the observation that among children living in high-risk situations, i.e., are exposed to events that may potentially impair their health or development, risk factors tend to co-occur. For instance, children exposed to war or natural disasters are particularly vulnerable to secondary adversities such as homelessness, malnutrition, parental loss, and community violence (Pynoos, Steinberg, \& Piacentini, 1999; Shaw, 2003). In this regard, a recent study conducted by our workgroup with Tamil children in Sri Lanka revealed that children who were affected by the Tsunami and the civil war also reported a particularly high number of experiences of family violence (Catani, Jacob, Schauer, Kohila, \& Neuner, 2008). Furthermore, a clear dose-effect relationship between exposure to various stressful experiences and PTSD was found in the Tamil children. These results show that the impact of family violence ought to be considered when investigating the cumulative effects of stressful experiences on children's well-being.

The aim of the present investigation was thus to establish the extent of cumulative traumatic and stressful experiences related to the war and family violence in a sample of school children in
Kabul. We assumed that a variety of risk factors such as poverty, exposure to the war, and general trauma load would be related to the amount of family violence reported by the children. By including these risk factors in a linear regression model we wanted to determine predictors of violence experienced by the children in their families.

Once we were confronted with the local situation of children in Kabul and realized during the initial interviews that many of the children had to work, mainly as carpet weavers, we systematically assessed the frequency and amount of child labor in our sample. We predicted that the amount of daily hours of forced work would be associated both with the amount of family violence experienced by the children as well as with the severity of PTSD symptoms. Assuming a dose-effect relationship between different stressors and PTSD, trauma symptom severity was furthermore expected to be related to the amount of exposure to war experiences, to family violence, and to overall trauma load.

In summary, by identifying adverse childhood experiences and their relationship with PTSD symptoms we hoped to reveal mechanisms to promote the understanding of the complex situation of children in a war-torn country, the variety of stressors they are confronted with, and the consequences for their mental health. Furthermore, findings of the present study could have implications for future intervention and prevention programs with children in Afghanistan as well as other resource poor countries affected by war and conflict.

\section{METHOD}

\section{Participants}

This study was designed as an epidemiological survey of schoolattending children in Kabul and was conducted in October 2005 in the Dashti Barchi area of the Afghani capital. Dashti Barchi is an urban district in Kabul, which has been particularly affected by war and violence due to the Taliban regime. Children from age 7-15 from two schools in close vicinity, a boys school and a girls school, took part in the survey. At the time of the survey, the tense security situation in Kabul prevented a random or systematic selection of schools for the survey. Rather, representatives of the Ministry of Education selected two schools based on safety conditions and a policy of evaluating the conditions of and providing support to ethnically mixed schools.

The condition of the school facilities were extremely bad and this had consequences for the randomization procedure of participants. Lists of school-attending children were not available. To ensure that children could be tracked again for validation interviews, entire classes were randomly chosen and included in the survey. In addition to the lack of attendance lists, records of children's home addresses were not available, nor was there any contact between teachers and caregivers. Therefore, it was not possible to inform parents about the survey or to obtain consent from the 
Table 1. Sociodemographic Characteristics for Boys and Girls

\begin{tabular}{lcccc}
\hline & \multicolumn{2}{c}{ Girls $(n=122)$} & \multicolumn{2}{c}{ Boys $(n=165)$} \\
\cline { 2 - 5 } & $M$ & $S D$ & & $S D$ \\
\hline Age & $11.8^{* * *}$ & 1.6 & 10.9 & 1.7 \\
Years spent abroad & 1.2 & 2.3 & 1.4 & 2.4 \\
Ratio household members/room & 4.4 & 2.6 & 4.1 & 2.1 \\
Weekly meals & 20.6 & 3.6 & 21.1 & 1.1 \\
Weekly meals with meat & 1.8 & 2.3 & 11.3 & 2.6 \\
Child possessions & $14.1^{* *}$ & 7.6 & 69.3 & 7.2 \\
Family possessions & $82.1^{*}$ & 40.0 & & 32.8 \\
\hline
\end{tabular}

Note. Symbols indicate significant differences between boys and girls.

${ }^{*} p<.05 .{ }^{* *} p<.01 .{ }^{* * *} p<.001$.

parents; thus, consent was obtained from the children, their teachers, school authorities, and the Ministry of Education. Approval for implementation of the survey was also obtained from the Ethical Review Board of the University of Konstanz, Germany.

The interviewed sample consisted of 287 children (122 girls, 165 boys) with ages ranging from 7-15 (mean age of the whole sample: 11 years). The majority of the children were Hazara (89.9\%), 5.6\% were Tadchik, $0.8 \%$ were Pashtun, and $3.5 \%$ were from other ethnicities. Of the sample, 9.2\% had lost their fathers and $3.4 \%$ had lost their mothers. Table 1 provides an overview of sociodemographic characteristics separately for boys and girls. The two samples differed significantly with respect to age and number of possessions. On average, girls were approximately one year older than boys and came from families with a higher number of possessions.

\section{Measures}

Dari language versions of all instruments were created using translation and blind back translation. Discrepancies were checked by experts and a final version was derived through extensive consultation with local counselors and a team of translators. For the questions related to sociodemography and physical health and for the war-related event list, a modified version of the child questionnaire previously employed in similar epidemiological surveys on war-affected children in Sri Lanka (Catani et al., 2008; Elbert et al., 2009) was used and adapted to the current conditions given in Kabul. A global index of economic status was calculated as the mean of the following standardized (z-transformed) variables: child possessions, family possessions, meals/week, and meals with meat/week.

In addition, the interview included a number of questions about the child's and parents' drug use and about being forced to work. The latter question was initially not part of the questionnaire but was added after the first few days of interviews in the boy's school when the problem of being forced to work was repeatedly addressed by the children. We therefore decided to include the question of whether a child is forced to contribute to the family's income generation (household duties up to 2 hours were not considered) as well as questions about the type of work and the average amount of daily work hours. Because of the delayed inclusion of the questions related to child labor, we only have these data for 79 out of the 165 boys who were interviewed. However, all 122 girls were asked about child labor.

Family violence experienced by children was defined as being exposed to physical, emotional, or sexual abuse as well as witnessing intimate partner violence between parents. For the assessment of adverse childhood experiences at home we used a questionnaire that had previously been used with children in other cultural contexts (Catani et al., 2008; Elbert et al., 2009) Following an in-depth discussion with local counselors and experts, the most suitable items for the Afghan culture were chosen and the wording was adapted. Because of religious and cultural norms, no detailed items addressing sexual abuse could be included in the questionnaire. However, sexual abuse was asked for in the event list of the PTSD diagnostic instrument using a less-detailed wording.

In the war event checklist, items such as "Have you been close to shelling or gunfire?" were used. With respect to family violence, children were asked, "Have things being thrown at you at home?" and "Have you seen a family member being injured with a weapon by another family member?" Exposure to aversive and traumatic life events and conditions was established by counting event types that were reported by the child separately for warrelated events that happened during the 12 months preceding the interview (scored as "last year") and those that happened more than 12 months prior to the interview (scored as "ever"). The family violence questions were aimed at determining if events had happened "last month" or "ever." Thus, it was possible to determine the number of cases in which there was ongoing family violence.

The University of California at Los Angeles PTSD Index (UPID) for children (Pynoos, Rodriguez, Steinberg, Stuber, \& Frederick, 1998) was used for the assessment of traumatic event 
types and resulting PTSD symptoms. The UPID has proven good psychometric properties and it has been used in a wide variety of cultural settings including child populations in postwar countries (Catani et al., 2008; Neuner, Schauer, Catani, Ruf, \& Elbert, 2006; Steinberg, Brymer, Decker, \& Pynoos, 2004). Instead of using the UPID as a self-assessment questionnaire, it was carried out as a structured interview by the trained counselors. We established the diagnosis of probable PTSD according to fulfillment of criteria according to the Diagnostic and Statistical Manual of Mental Disorders, Fourth Edition (DSM-IV; American Psychiatric Association, 1994) assessed through the corresponding 17 items of the UPID. An item was considered to indicate the presence of a PTSD symptom if it occurred at least once in the last week and produced clinical suffering. Because the UPID does not assess Criterion F for PTSD diagnosis, we added six items related to impairment in functioning or distress in different areas of children's life such as school, family life, friendships, general life satisfaction, and leisure activities. For instance, children were asked, "Have these symptoms (examples are given) caused you to have problems at school or at home?" and "Have these problems kept you from playing/socializing with your friends?"

A random subsample of 49 children (18 girls, 33 boys) was interviewed 1-2 weeks later by clinical experts experienced in work with traumatized individuals, using the help of interpreters (English-Dari). The Clinician Administered PTSD Scale for Children (Nader et al., 1996) was used to assess traumatic experiences and validate the diagnosis of probable PTSD established by local counselors with the UPID. The UPID diagnoses achieved a sensitivity of $76.9 \%$. Specificity was $83.4 \%$ indicating a slight overestimation of PTSD using the screening instrument UPID. Eightytwo percent of the decisions on PTSD diagnosis were matched between screening- and expert interviews $(\kappa=.56)$. Considering the fact that first, two different instruments have been used and second, diagnoses given by local counselors were compared to those given by clinical experts, and third there was a time interval between the assessments, the validation results indicate a satisfying degree of validity.

Validation interviews by clinical experts also included parts of the MINI International Neuropsychiatric Interview for Children and Adolescents English Version 2.0 (M.I.N.I. Kid; Sheehan et al., 1998) to screen for other psychiatric diagnoses often found to be comorbid with PTSD in children. Specifically, Sections A-major depressive episode, B-dysthymia, C—suicidality, G—separation anxiety disorder, $\mathrm{I}$-specific phobia, and $\mathrm{O}$-attention deficit hyperactivity disorder were used with the validation sample of children.

\section{Procedure}

Screening interviews were conducted by 34 local trauma counselors (17 women and 17 men) employed in 15 Caritas Centers for Psychosocial Counseling throughout Kabul. The counselors had been extensively trained by our workgroup in the administration of structured diagnostic interviews including the instruments used in this survey. Only male counselors interviewed boys, and only female counselors interviewed girls. Interviews conducted by local counselors were closely supervised by one or more clinical psychologists from our work group.

\section{RESULTS}

Frequency of somatic complaints was high with $62 \%$ of the children reporting headaches, $42.8 \%$ reporting diarrhea, and $42.5 \%$ of them complaining of a fever in the last month. The average number of somatic problems in the last 4 weeks was 3.1 ( $S D=$ 2.2) for the whole sample. There was no significant difference between boys and girls ( $M$ girls $=3.0, S D=2.1, M$ boys $=3.2$, $S D=3.0)$.

Drug intake did not turn out to be a noteworthy issue in children or in parents. Apart from some single cases (less than $1 \%$ ), children did not endorse any items related to drug use habits for themselves or their parents. Six percent of children reported tobacco use by their fathers.

Although the worst fights of the armed conflict had already occurred before their births, $51 \%$ of the children reported at least one type of war-related event. On average, children had experienced $1.53(S D=2.23)$ different types of war events in their life. $15 \%$ of the children reported a war-related event that occurred within the last year. With respect to lifetime exposure to the war, boys were affected more than girls with $58.8 \%$ of the boys reporting at least one type of war-related event compared to $40.2 \%$ of the girls. In addition, the average number of different types of lifetime war experiences was significantly higher in boys (1.78 events in the boy sample vs. 1.18 events in girls), $t(d f 285)=2.28, p<.05$. The most frequent event types were having been badly beaten by militias or other armed personnel (18.3\% of the whole sample), being close to shelling and gunfire (16.8\%), and witnessing somebody else being severely beaten or tortured by armed personnel $(22.5 \%)$.

Lifetime exposure to violence experienced at home was high, with $77 \%$ of children $(71.3 \%$ girls, $81.3 \%$ of the boys) reporting at least one event type in the family violence spectrum. On average, children reported having experienced or witnessed 4.3 ( $S D=$ 4.5) different violent event types happening in their families. Again, there was a difference between genders with boys reporting significantly more experiences of family violence compared to girls ( $M$ boys: $5.0, S D=4.8, M$ girls: $3.5, S D=3.9), t(d f 285)=$ $2.71, p<.01$.

In addition, ongoing violence at home appeared to be common, with $35.2 \%$ of the interviewed children $(35.3 \%$ of the girls, $35.1 \%$ of the boys) having experienced or witnessed at least one aversive event in the last month. Figure 1 provides a more detailed look at the specific types of lifetime events described by children. 


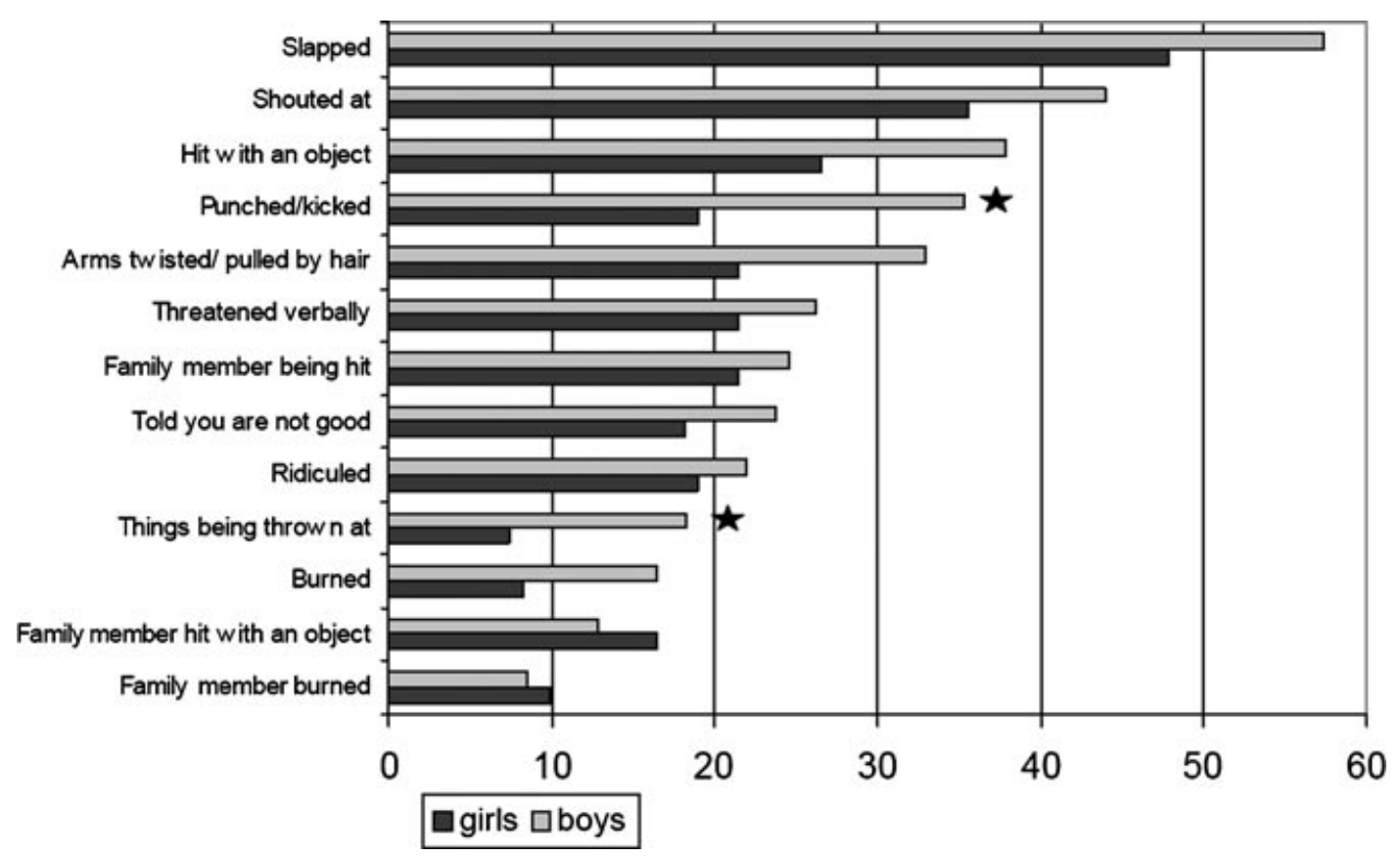

Figure 1. Percentages of children ever exposed to different types of family violence acts ${ }^{*}$ indicates $\chi^{2}$ comparison between boys and girls). $p<.05$.

Eleven percent of the children had suffered at least one injury (bruises, bleedings, and broken bones) because of the violent treatment at home, and $9 \%$ of them had needed medical treatment on at least one occasion. Again, there were significant differences between boys and girls. Whereas $15.7 \%$ of the boys reported having suffered injuries due to the violence and $11.4 \%$ of them had needed medical treatment, the corresponding percentages for girls were $5.8 \%$ and $4.9 \%$ : for injuries $\chi^{2}(1, N=280)=6.79, p<.01$; for medical treatment $\chi^{2}(1, N=280)=3.61, p<.05$.

Nearly a quarter $(23.2 \%)$ of the sample reported having ever witnessed other family members being hit. When asked about the dynamics of physical aggression taking place at home, $41.6 \%$ of the children reported being beaten by the father, $59.9 \%$ said they were beaten by the mother, and in $37.8 \%$ of the cases, the child was also beaten by an older sibling. In addition, $31.5 \%$ of the children had witnessed their mother being beaten by the father.

Child labor was found to be very common in the children asked about forced work, with $48.7 \%$ of the boys compared to $29 \%$ of the girls reporting daily work, $\chi^{2}(1, N=162)=8.14, p<.01$. On average, children forced to contribute to the family's income generation worked 6.7 hours/day $(S D=3.01)$ with a range of $1-13$ hours/day. In children affected by child labor, there was no significant difference between genders with respect to the average amount of daily work ( $M$ boys: $6.6, S D=2.9, M$ girls: $6.7, S D=3.1$ ). The majority of children who reported working held jobs as carpet weavers. Seven boys also reported working in small retail stores.
The analysis of the UPID data revealed that $42 \%$ of the children (30.3\% of the girls and $51.5 \%$ of the boys) reported an event that fulfilled the A1 criterion for traumatic event according to the DSM-IV. Figure 2 shows the percentages of boys and girls exposed to different types of traumatic events. Again, there were substantial differences between genders with boys having been exposed more often to the war (18.6\% vs. $5 \%), \chi^{2}(1, N=287)$ $=11.60, p<.001$, to painful medical treatment ( $5 \%$ vs. $1.1 \%)$, $\chi^{2}(1, N=287)=4.71, p<.05$, and to other types of traumatic experiences $(9.6 \%$ vs. $2.5 \%), \chi^{2}(1, N=287)=7.86, p<.01$. Also, boys reported having been beaten up in town more often than girls, $6.4 \%$ vs. $1.8 \% ; \chi^{2}(1, N=287)=4.58, p<.05$.

Of the girls, $14.1 \%$ and $26.1 \%$ of the boys fulfilled all $D S M$ $I V$ criteria for probable PTSD, $\chi^{2}(1, N=282)=6.05, p<.05$. Table 2 provides an overview of severity scores, number of trauma symptoms, as well as functional impairments in both samples.

Results of the M.I.N.I. interviews that were conducted by clinical experts with the validation subsample $(n=49)$ did not show a particularly increased prevalence of other psychological disorders. Only two children did fulfill DSM-IV criteria for a diagnosis of major depressive disorder whereas in three other cases, a separation anxiety disorder was diagnosed. Dysthymia, specific phobia, or attention-deficit hyperactivity disorder could not be diagnosed in any child in the validation sample.

To examine potential predictors of family violence experienced by a child, we calculated linear regression models separately for 


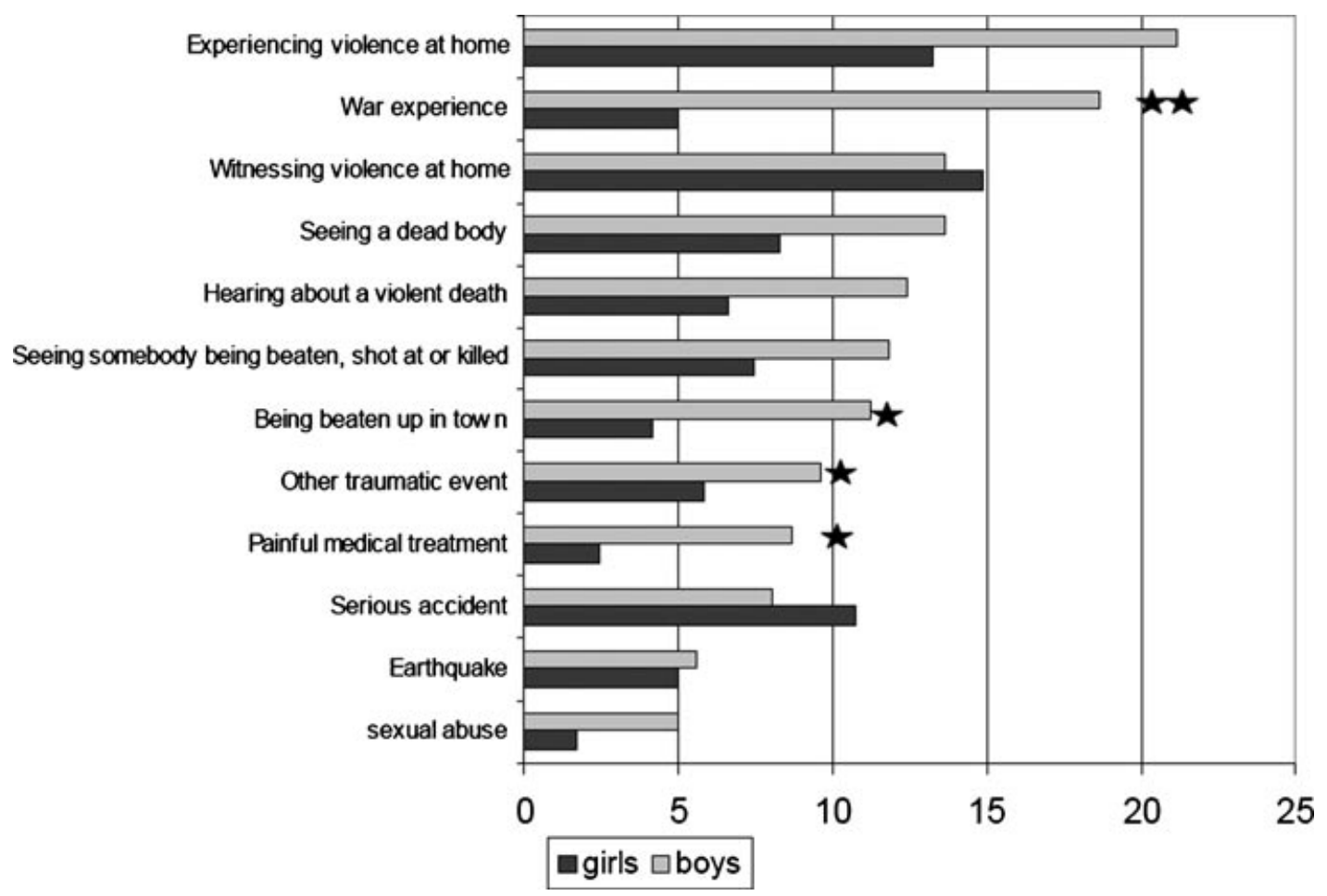

Figure 2. Percentages of children exposed to different types of traumatic events (UPID checklist; ${ }^{*}$ indicates $\chi^{2}$ comparison between boys and girls).

${ }^{*} p<.05 .{ }^{* *} p<.01$.

Table 2. Posttraumatic Stress Disorder (PTSD) Prevalence Rates and Trauma Symptom Severity

\begin{tabular}{|c|c|c|c|c|}
\hline & \multicolumn{2}{|c|}{ Girls } & \multicolumn{2}{|c|}{ Boys } \\
\hline & $M$ & $S D$ & $M$ & $S D$ \\
\hline PTSD severity score for children with PTSD & $34.9^{* *}$ & 10.3 & 25.7 & 10.9 \\
\hline PTSD severity score & 6.8 & 13.9 & 9.5 & 12.8 \\
\hline PTSD symptoms & $2.7^{* *}$ & 5.1 & 4.9 & 5.8 \\
\hline Impaired areas of psychosocial functioning & $0.45^{*}$ & 1.0 & 0.83 & 1.3 \\
\hline
\end{tabular}

Note. Symbols indicate significant differences between boys and girls.

${ }^{*} p<.05 .{ }^{* *} p<.01 .{ }^{* * *} p<.001$.

girls and boys. The dependent variable was the total number of family violence event types reported by the children. Because of the missing information with respect to child labor in half of the male sample, only 79 boys could be included in the regression analysis. Results of the analyses are presented in Tables 3 and 4.

To determine significant relationships between adverse childhood experiences (amount of child labor, number of war experiences, and number of family violence experiences) and clinical variables (somatic complaints, areas of impaired functioning, and PTSD symptom severity score), we calculated Pearson's correlation coefficients (one-tailed) for each pair of variables, separately for girls and boys. Only children who had reported at least one traumatic experience in the UPID event checklist were included in the analyses. With respect to the boys' sample, again we only included participants who had been asked about child labor. Results of the analyses are given in Table 5.

\section{DISCUSSION}

By examining adverse life experiences and PTSD symptoms in Kabul, Afghanistan, we found strong gender differences with respect to the frequency of adverse childhood experiences as well as 
Table 3. Standardized Beta Coefficients and Correlation Coefficients Resulting From a Linear Regression Model on the Amount of Family Violence Reported by Girls

\begin{tabular}{lcr}
\hline Predictor & \multicolumn{1}{c}{$r$} \\
\hline Age & .05 & .21 \\
Mother alive (no) & .03 & -.11 \\
Father alive (no) & .04 & -.02 \\
Household members per room & .00 & .08 \\
Economic Status & -.05 & -.16 \\
Average hours of child work/day & $.24^{* *}$ & .42 \\
Number of traumatic events & $.20^{*}$ & .57 \\
Previous exposure to war & $.39^{* * *}$ & .50 \\
\hline
\end{tabular}

Note. Full model's adjusted $R^{2}=.40 ; F(8,105)=10.58, p<.0001$.

Zero-order correlation is represented by Spearman's Rho for continuous predictor variables and point-biserial correlation for dichotomous predictor variables. Symbols indicate significant $\beta$.

${ }^{*} p<.05 .{ }^{* *} p<.01$. *** $p<.001$.

Table 4. Standardized Beta Coefficients and Correlation Coefficients Resulting From a Linear Regression Model on the Amount of Family Violence Reported by Boys

\begin{tabular}{lcr}
\hline Predictor & \multicolumn{1}{c}{ ß } & \multicolumn{1}{c}{$r$} \\
\hline Age & -.11 & -.04 \\
Mother alive (no) & -.09 & .12 \\
Father alive (no) & -.10 & -.04 \\
Household members per room & -.10 & -.07 \\
Economic status & -.11 & -.07 \\
Average hours of child work/day & .14 & .19 \\
Number of traumatic events & $.64^{* * *}$ & .65 \\
Previous exposure to war & -.03 & .43 \\
\hline
\end{tabular}

Note. Full model's adjusted $R^{2}=.41 ; F(9,68)=7.05, p<.001$. Symbols indicate significant $B$.

$* * * p<.001$

regarding the relationship between different types of stressors and their association with PTSD symptoms. Boys reported a higher amount of family violence, war experiences, as well as general traumatic events. Consequently, probable PTSD prevalence was significantly higher in boys than in girls ( $26.1 \%$ vs. $14.1 \%)$. The strong impact of gender on the frequency of traumatic events might be explained to some extent by the cultural characteristics of Afghan Muslim families where girls more than boys are mostly kept inside the house thereby diminishing their risk of exposure to traumatic events such as war or community violence in the streets. This assumption is supported by a previous study with Palestinian school children where boys were found to be exposed to a greater number of traumatic events resulting in a higher PTSD prevalence in boys compared to girls (Khamis, 2000).
A cross-national comparison of family violence data is difficult as there is a paucity of representative data on child maltreatment prevalence rates (Straus, Hamby, Finkelhor, Moore, \& Runyan, 1998). Estimates based on surveys in communities and child protection services (Gateway, 2006) indicate prevalence rates of severe physical abuse between 1 and $5 \%$ in the United States. Considering that in the present study $15.7 \%$ of the boys in our sample reported having suffered at least one injury resulting from maltreatment at home, we tentatively conclude that the level of child maltreatment found in Afghan boys can be regarded as exceptionally high. Our results indicate that other forms of family violence seem also to be high as spouse beating was witnessed by $31.5 \%$ of the children. This result fits earlier findings that adverse childhood experiences tend to co-occur, thereby increasing the risk for detrimental mental health outcome (Appel \& Holden, 1998; Margolin \& Vickerman, 2007). The estimates for the occurrence of sexual violence in the present survey have to be considered with caution, as we could not address this form of abuse with more specific questions.

A special finding of the present survey was the high rate of child labor. Nearly half of the boys and a third of the girls reported to be forced to work about 7 hours daily. It is known from a few reports on the situation of children in Afghanistan that many families are reliant on the earning capacity of their children (Afghanistan Independent Human Rights Commission, 2007) resulting in estimated 36,000 children who are working as carpet weavers in Kabul alone (Cooperation Center for Afghanistan, 2002).

Not much is known, so far, about consequences of child labor for mental health impairments. To our knowledge, only one survey with children in the Ethiopian capital has addressed this topic showing that the rate of any childhood emotional and behavioral psychiatric disorder was double as high in child laborers compared to nonlaborers (Fekadu, Alem, \& Hagglof, 2006). The present data show that child labor increases the likelihood of being maltreated in their homes at least for girls. This is in line with our initial assumption that childhood adversities tend to co-occur in particular in children living in a high-risk environment such as Kabul.

In boys, the only significant predictor of family violence was the amount of previous types of traumatic experiences, which could be explained by the fact that traumatic events were much more common among boys. The link between prior trauma and the amount of family violence confirms the previous findings in child survivors of the war and the Tsunami in Sri Lanka (Catani et al., 2008).

Contrary to our prediction, poverty did not significantly predict family violence even though, in the past, it has been repeatedly linked to an increased risk for child abuse (Tolan et al., 2006). However, as the present sample of children was taken from the Hazara community located in one of the poorest and most war affected districts in Kabul, the lack of predictive power of economic status might be due to a bottom-effect.

Consequences of the extensive amount of childhood adversities and traumatic experiences reported by our sample are reflected in 
Table 5. Correlations Between Adverse Childhood Experiences and Clinical Variables for Boys $(N=40)$ and Girls $(N=37)$ With at Least One Traumatic Event Type

\begin{tabular}{cccccccc}
\hline & $\begin{array}{c}\text { (1) Hours of } \\
\text { forced work/day }\end{array}$ & $\begin{array}{c}\text { (2) Amount of } \\
\text { war exposure }\end{array}$ & $\begin{array}{c}\text { (3) Amount of } \\
\text { family violence }\end{array}$ & $\begin{array}{c}\text { (4) Traumatic } \\
\text { event types }\end{array}$ & $\begin{array}{c}\text { (5) Somatic } \\
\text { complaints }\end{array}$ & $\begin{array}{c}\text { (6) Functioning } \\
\text { impairment }\end{array}$ & $\begin{array}{c}\text { (7) PTSD } \\
\text { symptom score }\end{array}$ \\
\hline$(1)$ & - & .03 & -.06 & -.02 & -.07 & -.02 & .02 \\
$(2)$ & .26 & - & .25 & $.52^{* *}$ & -.09 & -.00 & .25 \\
$(3)$ & $.48^{* *}$ & $.40^{* *}$ & - & $.62^{* *}$ & $.34^{*}$ & -.03 & .13 \\
$(4)$ & $.36^{*}$ & $.55^{* *}$ & $.46^{* *}$ & - & .22 & .19 & $.30^{*}$ \\
$(5)$ & .06 & .20 & $.30^{*}$ & .19 & - & .23 & .13 \\
$(6)$ & $.31^{*}$ & $.54^{* *}$ & $.51^{* *}$ & $.45^{* *}$ & $.30^{*}$ & - & $.47^{* *}$ \\
$(7)$ & .27 & $.32^{*}$ & $.45^{* *}$ & $.40^{* *}$ & $.39^{* *}$ & $.38^{* *}$ & - \\
\hline
\end{tabular}

Note. Coefficients for boys are shown in the upper right triangle; coefficients for girls are reported in the lower left triangle.

${ }^{*} p<.05$ for one-tailed test. ${ }^{* *} p<.01$.

high prevalence rates of PTSD. About one in four of the boys and $15 \%$ of the girls were diagnosed with PTSD, confirming previous studies in conflict populations (Saigh, 1991; Schaal \& Elbert, 2006). However, the ratio of the number of traumatic event types and PTSD prevalence seems to be exceptionally high in the present sample. In boys and girls, half of the children who had experienced at least one traumatic event developed PTSD whereas this was the case for only less than a third of the trauma-affected Sri Lankan children (Catani et al., 2008). Thus, it seems that the context in Afghanistan, including factors such as child labor and poverty might constitute a particularly vulnerable environment for the development or maintenance of PTSD. Furthermore, we found a high amount of physical symptoms in the children, in particular headaches, diarrhea, and fever. In girls, these physical problems were significantly related to PTSD symptom severity. This is in agreement with existing research arguing for a strong link between trauma and PTSD and poor physical health (Schnurr \& Green, 2003).

Our initial assumption of a cumulative effect of different stressors on PTSD was confirmed at least in the girls' sample where various types of adverse experiences were significantly associated with PTSD severity. The strong relationship between violence experienced at home and PTSD highlights once again the importance of family violence in the context of organized violence (Catani et al., 2008).

With respect to the boys, only the amount of traumatic event was found to be related to PTSD symptoms. However, this could be also due to the fact that correlation analyses were not able to control for probable interrelationships between the different variables that might have an influence on the development of PTSD symptoms. Unfortunately, sample size was too small to calculate a regression analysis on PTSD, separately for each gender.

In fact, the small sample size is a limitation of the present study. In addition, because we could only examine school children of two schools in a specific district of Kabul, our sample is probably far from representative for the entire Afghan child population. The complex relationship between types of adverse childhood experiences and mental health outcomes highlights the need of large-scale surveys in conflict areas.

Taken together, data of the present study indicate that children in a war-torn society such as Afghanistan are typically not only affected by war events, but also by other major stressors, such as family violence, child labor, and poverty. Conversely, it appears as if the interplay of these multilevel stressors contributes to a higher vulnerability of the children when exposed to traumatic experiences. Our data emphasize that psychological treatment approaches for children in postconflict settings should be carefully tailored to fit the specific requirements of the given population and address problems present at the family and community level, which may arise as an indirect consequence after violent conflict.

\section{REFERENCES}

Afghanistan Independent Human Rights Commission. (2007). Research ReportThe General Situation of Children in Afghanistan. Kabul: Author.

Allwood, M. A., Bell-Dolan, D., \& Husain, S. A. (2002). Children's trauma and adjustment reactions to violent and nonviolent war experiences. Journal of the American Academy of Child and Adolescent Psychiatry, 41, 450-457.

American Psychiatric Association. (1994). Diagnostic and statistical manual of mental disorders (4th ed.). Washington, DC: Author.

Appel, A. E., \& Holden, G. W. (1998). The co-occurence of spouse and physical child abuse: A review and appraisal. Journal of Family Psychology, 12, 578-599.

Cardozo, B. L., Bilukha, O. O., Crawford, C. A., Shaikh, I., Wolfe, M. I., Gerber, M. L., et al. (2004). Mental health, social functioning, and disability in postwar Afghanistan. Journal of the American Medical Association, 292, 575-584.

Catani, C., Jacob, N., Schauer, E., Kohila, M., \& Neuner, F. (2008). Family violence, war, and natural disasters: A study of the effect of extreme stress on children's mental health in Sri Lanka. BMC Psychiatry, 8: 33.

Cooperation Center for Afghanistan. (2002). A Summary Report on Children Situation in Afghanistan 2000. Kabul: Author.

Elbert, T., Schauer, M., Schauer, E., Huschka, B., Hirth, M., \& Neuner, F. (2009). Trauma-related impairment in children-An epidemiological survey in Sri Lankan provinces affected by armed conflict. Child Abuse and Neglect, 33, 238-246. 
Fekadu, D., Alem, A., \& Hagglof, B. (2006). The prevalence of mental health problems in Ethiopian child laborers. Journal of Child Psychology and Psychiatry, 47, 954-959.

Gateway, C. W. I. (2006). Child abuse and neglect fatalities. Statistics and interventions-numbers and trends. Child Welfare Information Gateway. Retrieved April 5, 2009, from http://www.childwelfare.gov/pubs/factsheets/ fatality.cfm

Khamis, V. (2000). Child psychological maltreatment in Palestinian families. Child Abuse and Neglect, 24, 1047-1059.

Margolin, G., \& Vickerman, K. A. (2007). Posttraumatic stress in children and adolescents exposed to family violence: I. Overview and issues. Professional Psychology: Research and Practice, 38, 613-619.

Mashal, T., Takano, T., Nakamura, K., Kizuki, M., Hemat, S., Watanabe, M., et al. (2008). Factors associated with the health and nutritional status of children under 5 years of age in Afghanistan: Family behaviour related to women and past experience of war-related hardships. BMC Public Health, 8, 301.

Mghir, R., Freed, W., Raskin, A., \& Katon, W. (1995). Depression and posttraumatic stress disorder among a community sample of adolescent and young adult Afghan refugees. Journal of Nervous and Mental Disease, 183, $24-30$.

Mghir, R., \& Raskin, A. (1999). The psychological effects of the war in Afghanistan on young Afghan refugees from different ethnic backgrounds. International Journal of Social Psychiatry, 45, 29-36; discussion 36-40.

Nader, K. O., Kriegler, J. A., Blake, D. D., Pynoos, R. S., Newman, E., \& Weathers, F. W. (1996). Clinician Administered PTSD Scale for children and adolescents for DSM-IV. Los Angeles: National Centre for PTSD and UCLA Trauma Psychiatry Program, Department of Psychiatry, UCLA School of Medicine.

Neuner, F., Schauer, E., Catani, C., Ruf, M., \& Elbert, T. (2006). Post-tsunami stress: A study of posttraumatic stress disorder in children living in three severely affected regions in Sri Lanka. Journal of Traumatic Stress, 19, 339-347.

Pynoos, R. S., Rodriguez, N., Steinberg, A., Stuber, M. L., \& Frederick, C. (1998). UCLA PTSD Index for DSM-IV. Unpublished manuscript, University of California at Los Angeles, Los Angeles, CA.

Pynoos, R. S., Steinberg, A. M., \& Piacentini, J. C. (1999). A developmental psychopathology model of childhood traumatic stress and intersection with anxiety disorders. Biological Psychiatry, 46, 1542-1554.
Rasekh, Z., Bauer, H. M., Manos, M. M., \& Iacopino, V. (1998). Women's health and human rights in Afghanistan. Journal of the American Medical Association, $280,449-455$.

Saigh, P. A. (1991). The development of posttraumatic stress disorder following four different types of traumatization. Behaviour Research and Therapy, 29, $213-216$.

Schaal, S., \& Elbert, T. (2006). Ten years after the genocide: Trauma confrontation and posttraumatic stress in Rwandan adolescents. Journal of Traumatic Stress, 19, 95-105.

Schnurr, P. P., \& Green, B. L. (2004). Trauma and health: Physical health consequences of exposure to extreme stress. Washington, DC: American Psychological Association.

Scholte, W. F., Olff, M., Ventevogel, P., de Vries, G. J., Jansveld, E., Cardozo, B. L., et al. (2004). Mental health symptoms following war and repression in eastern Afghanistan. Journal of the American Medical Association, 292, 585-593.

Shaw, J. A. (2003). Children exposed to war/terrorism. Clinical Child and Family Psychology Review, 6, 237-246.

Sheehan, D. V., Lecrubier, Y., Sheehan, K. H., Amorim, P., Janavs, J., Weiller, E., et al. (1998). The Mini-International Neuropsychiatric Interview (M.I.N.I.): The development and validation of a structured diagnostic psychiatric interview for DSM-IV and ICD-10. Journal of Clinical Psychiatry, 59(Suppl. 20), 22-33; quiz 34-57.

Steinberg, A. M., Brymer, M. J., Decker, K. B., \& Pynoos, R. S. (2004). The University of California at Los Angeles Post-traumatic Stress Disorder Reaction Index. Current Psychiatry Reports, 6, 96-100.

Straus, M. A., Hamby, S. L., Finkelhor, D., Moore, D. W., \& Runyan, D. (1998). Identification of child maltreatment with the Parent-Child Conflict Tactics Scales: Development and psychometric data for a national sample of American parents. Child Abuse and Neglect, 22, 249-270.

Thabet, A. A., Abed, Y., \& Vostanis, P. (2004). Comorbidity of PTSD and depression among refugee children during war conflict. Journal of Child Psychology and Psychiatry, 45, 533-542.

Tolan, P., Gorman-Smith, D., \& Henry, D. (2006). Family violence. Annual Reviews of Psychology, 57, 557-583.

United Nation's Children's Fund (UNICEF). (2007). The state of the world's children. Geneva: Author. 